DOI: $10.33947 / 1980-6469-v 15 n 1-4018$

\title{
O RACISMO CAMUFLADO PELO BULLYING
}

\author{
THE RACISM CAMOUFLAGED BY BULLYING
}

Raquel Carapello ${ }^{1}$

\section{RESUMO}

Este artigo busca evidenciar a diferença entre racismo e bullying e a dificuldade dos professores em lidar com as questões raciais presentes nas relações escolares e até mesmo em reconhecê-las no cotidiano de sala de aula. Procura problematizar a origem do mito da democracia racial que minimiza e dificulta o reconhecimento e consequentemente o combate ao racismo em nosso país, bem como os impactos desse discurso na construção da identidade étnico-racial dos negros no Brasil. A escola é um espaço privilegiado onde são estabelecidos vínculos e relações importantes na construção das identidades dos sujeitos e onde se constituem valores necessários à formação integral do ser humano considerando todas as suas dimensões. Respeitar a diversidade, a pluralidade cultural, conviver, cooperar, ser solidário, exercitar a empatia também são aprendizagens que devem ocorrer na escola e para tanto é necessário oportunizar espaços e situações que potencializem essa construção, com mediação e intencionalidade.

PALAVRAS-CHAVE: Racismo. Bullying. Democracia racial e identidade étnico-racial.

\section{ABSTRACT}

This article seeks to highlight the difference between racism and bullying and the teachers' difficulty in dealing with the racial issues present in school relations and even in recognizing them in the classroom everyday. Try to problematizethe origin of the myth of racial democracy that minimizes and hinders the recognition and consequently the fight against racism in our country, as well as the impacts of this discourse in the construction of the ethnic-racial identity of blacks in Brazil. The school is a privileged space where important links and relationships are established in the construction of the identities of the subjects and where values are necessary for the integral formation of the human being considering all its dimensions. Respecting diversity, cultural plurality, living together, cooperating, being supportive, exercising empathy are also learning that must occur in school and for this purpose it is necessary to provide spaces and situations that enhance this construction, with mediation and intentionality.

KEYWORDS: Racism. Bullying. Racial democracy and ethnic-racial identity.

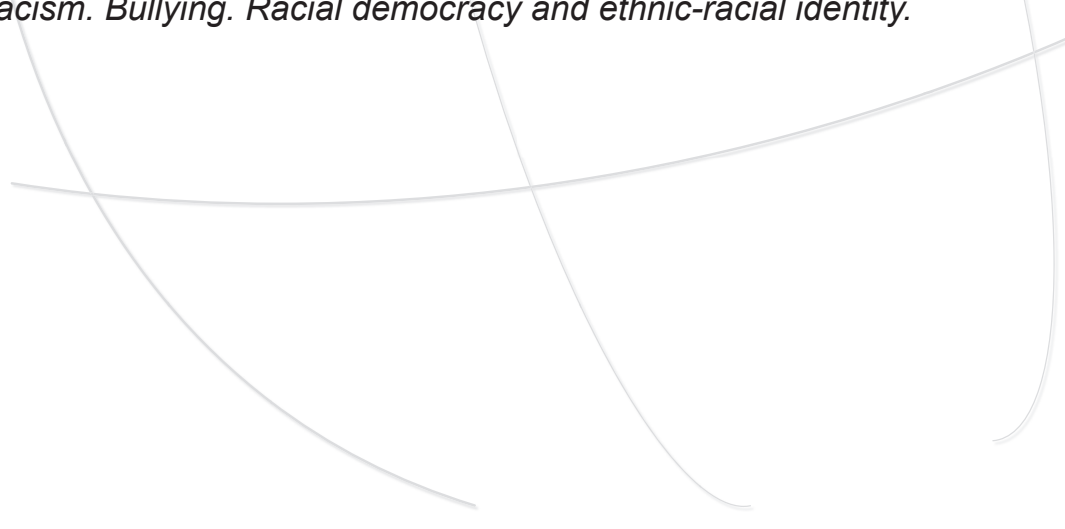

1 Graduada em pedagogia. Professora de Educação Infantil e Coordenadora de Programas Educacionais na Prefeitura Municipal de Guarulhos. 


\section{Introdução}

Existe uma questão ainda pouco discutida e urgente, especialmente em nosso país, que é o racismo sofrido pelas crianças negras na escola, este que por vezes é minimizado pelo discurso da "brincadeira", da "chacota" e até mesmo do bullying.

A pesquisadora e educadora Cleo Fante nos auxilia a compreender o que significa o termo bullying ao definir:

[...] bullying é um conjunto de atitudes agressivas, intencionais e repetitivas que ocorrem sem motivação evidente, adotado por um ou mais alunos contra outro (s), causando dor, angústia e sofrimento. Insultos, intimidações, apelidos cruéis, gozações que magoam profundamente, acusações injustas, atuação de grupos que hostilizam, ridicularizam e infernizam a vida de outros alunos levando-os à exclusão, além de danos físicos, morais e materiais, são algumas das manifestações do "comportamento bullying". (FANTE, 2005, p. 28 - 29 apud SILVA E ROSA, 2013, p.333).

É notório o quão nocivo são as agressões físicas e emocionais causadas pelo bullying e como elas afetam quem sofre essas agressões, as pratica e até mesmo as presencia. Bullying não é brincadeira, não é engraçado e não deve ser banalizado, não pode ser aceito como normal ou como característico das relações entre as crianças, bem como não pode ser utilizado para camuflar o racismo sofrido pelos negros na escola.

Quando as ofensas, as agressões, a violência sofrida pelos sujeitos está relacionada à sua cor, aos seus traços e à sua história, isso não é bullying, é racismo.

A ideia deste artigo surgiu a partir de uma cena presenciada no portão de uma escola no momento da saída dos educandos, um grupo de alunos jogando farelo de bolacha no cabelo Black Power de uma garota negra. Ao som de risos, piadas jocosas acerca de seus cabelos e sobre a dificuldade que teria em lidar com aquela situação, ela esboçou um sorriso "amarelo", entrou na "lotação" e, extremamente constrangida, tentou tirar os farelos que teimavam em se emaranhar em seus cabelos. Ela estava cercada por meninas brancas e a elas nada ocorreu. Uma destas meninas entrou com ela no veículo, mas não teve palavras de consolo para a colega e na verdade ninguém teve. Ao ver a cena, lágrimas não puderam ser contidas, ela foi mais forte, ela não chorou, mas sua tristeza era tão nítida e cortante que impulsionou a pesquisa sobre este tema e a realização desta discussão. Não é possível que a escola ainda seja um espaço de sofrimento para os educandos negros reproduzindo ações, discursos e ideias racistas ao invés de problematizá-los e combatê-los.

Ainda há grande resistência em se admitir que existe racismo no Brasil e quando este é cogitado, é banalizado, é visto como exagero, ou mesmo como algo natural, herança da era escravocrata que foi superada com a ascensão de classes, é invisibilizado pelo discurso que somos todos iguais, humanos e temos as mesmas oportunidades, basta esforçar-se, fazer por merecer. Nesse sentido, a doutora em Educação, filósofa e ativista Sueli Carneiro destaca:

O pensamento social brasileiro tem longa tradição no estudo da problemática racial e, no entanto, em quase toda a sua história, as perspectivas teóricas que o recortaram respondem, em grande parte, pela postergação do reconhecimento da persistência de práticas discriminatórias em nossa sociedade (CARNEIRO, 2011, p.16).

Este é um tema importante sobre o qual é necessária a reflexão, o diálogo e um posicionamento das instituições, especialmente as escolares, dos familiares e da sociedade. Não é possível conceber que crianças e adolescentes negros sofram com medo de frequentar a escola, sintam-se acuados, constrangidos e ao buscar apoio ou até mesmo compreensão sejam estimulados a relevar estas agressões e discursos, tenham sua dor minimizada e naturalizada.

\section{As relações sociais e o racismo na escola}

O racismo sofrido pelos educandos desde a primeira infância foi alvo de uma pesquisa realizada pela educadora Eliane Cavalleiro (1998) e seus resultados são apresentados no livro Do Silêncio escolar: racismo, discriminação e preconceito na educação infantil publi- 
cado em 27 de outubro de 2000. Em sua tese de mestrado, que deu origem ao livro, a autora ressalta que em sua experiência profissional já observava a influência das questões raciais nas relações que se estabeleciam na educação infantil entre as crianças e com os professores, o que lhe fez pesquisar sobre o tema:

A ideia desta pesquisa começou a florescer no segundo semestre de 1995, por ocasião de meu ingresso no NEINB-USP ${ }^{2}$, que ocorreu simultaneamente à minha experiência profissional em uma escola de educação infantil por mais de quatro anos. A relação diária com crianças de quatro a seis anos permitiu-me identificar que, nesta faixa de idade, crianças negras já apresentam uma identidade negativa em relação ao grupo étnico a que pertencem. Em contrapartida, crianças brancas revelam um sentimento de superioridade, assumindo em diversas situações atitudes preconceituosas e discriminatórias, como por exemplo, xingando e ofendendo as crianças negras, atribuindo à cor da pele caráter negativo.

Essas situações de discriminação, ocorridas na presença de professores, sem que estes interferissem, chamaram minha atenção. Os educadores não perceberam o conflito que se delineava. Talvez por não saberem lidar com tal problema, preferiram o silêncio (CAVALEIRO, 1998, p.11).

Neste trabalho a autora destaca os problemas ocasionados pela omissão dos professores em relação ao racismo e à discriminação que ocorrem na escola:

O silêncio dos professores perante as situações de discriminação impostas pelos próprios livros escolares acaba por vitimar os estudantes negros. Esse ritual pedagógico, que ignora as relações étnicas estabelecidas no espaço escolar, pode estar comprometendo o desempenho e o desenvolvimento da personalidade de crianças e de adolescentes negros, bem como estar contribuindo para a formação de crianças e de adolescentes brancos com um sentimento de superioridade (CAVALEIRO, 1998, p.52).

2 NEINB/USP - Núcleo de Pesquisas e Estudos Interdisciplinares do Negro Brasileiro.
A Lei Federal n. 10.639 de 2003 foi uma conquista de negros e negras, já que inclui no currículo oficial dos Sistemas Educativos a obrigatoriedade da temática "História e Cultura Afro-Brasileira" com vistas a possibilitar que os educandos possam conhecer meIhor nossas raízes, nossa história e que especialmente os educandos negros possam se reconhecer nessa história e nessa cultura, e valorizá-las podendo identificar-se e perceber-se pertencente à sua ancestralidade, construindo a consciência de sua raça e etnia.

LEI No 10.639, DE 9 DE JANEIRO DE 2003.

Altera a Lei no 9.394, de 20 de dezembro de 1996, que estabelece as diretrizes e bases da educação nacional, para incluir no currículo oficial da Rede de Ensino a obrigatoriedade da temática "História e Cultura Afro-Brasileira", e dá outras providências.

Art. 1o A Lei no 9.394, de 20 de dezembro de 1996, passa a vigorar acrescida dos seguintes arts. 26-A, 79-A e 79-B:

Art. 26-A Nos estabelecimentos de ensino fundamental e médio, oficiais e particulares, tornase obrigatório o ensino sobre História e Cultura Afro-Brasileira.

$\S 1$ O O conteúdo programático a que se refere o caput deste artigo incluirá o estudo da História da África e dos Africanos, a luta dos negros no Brasil, a cultura negra brasileira e o negro na formação da sociedade nacional, resgatando a contribuição do povo negro nas áreas social, econômica e política pertinentes à História do Brasil.

$\S 2^{\circ}$ Os conteúdos referentes à História e Cultura Afro-Brasileira serão ministrados no âmbito de todo o currículo escolar, em especial nas áreas de Educação Artística e de Literatura e História Brasileiras.

[...] Art. 79-B. O calendário escolar incluirá o dia 20 de novembro como 'Dia Nacional da Consciência Negra'. (BRASIL, 2003).

Porém, em seu livro $O$ mito da democracia racial: Um debate marxista sobre raça, classe e identidade, Wilson Honório da Silva destaca que nesta lei foi vetado o artigo que destinava mais verbas para a 
formação de professores e afirma que "disso resulta que, na prática, não temos professores suficientes nem com a formação necessária para ensinar os novos conteúdos de história e cultura afro-brasileiras" (SILVA, 2016, p.81).

O despreparo de professores e instituições escolares para lidar com o racismo, o preconceito e a discriminação que ocorre entre os envolvidos nos espaços escolares acaba por reforçar essas relações e desconsidera os prejuízos que elas podem ocasionar a todos.

Estas relações raciais também estão presentes no ensino superior e assim como os demais espaços escolares, educacionais, as universidades também não estão preparadas para lidar e para combater estas relações, inclusive perpetuando, muitas vezes, a desigualdade, privilegiando discursos eurocêntricos em detrimento de outros e cerceando o acesso de educandos e educadores negros em suas salas de aula.

Wilson Honório da Silva (2016) também problematiza as relações sociais estabelecidas na universidade, mais especificamente na USP e destaca o quanto o mito da democracia racial pode ser usado para camuflar estas relações baseadas na desigualdade.

[...] A democracia na USP é letra morta, tanto do ponto de vista político quanto, principalmente, do ponto de vista racial. É muito provável, por exemplo, que muitos de vocês, nos próximos quatro ou cinco anos, nunca tenham aula com sequer um professor ou professora negro, já que, segundo uma pesquisa realizada há alguns anos, eles compõem exatos $0,9 \%$ do corpo docente. Mas, no entanto, temos certeza que vocês verão muitos negros e negras como funcionários ou exercendo trabalhos precarizados ou terceirizados, nos quais nossos irmãos e irmãs são cerca de $70 \%$.

Ao mesmo tempo a possibilidade de ter colegas negros na sala de aula é bastante reduzida. Para se ter uma ideia, basta, citar dados revelados pela Fuvest em 2013. Os números são de enojar. Naquele ano, as três carreiras mais concorridas do vestibular da USP (Medicina, Engenharia Civil em São Carlos, e publi- cidade e propaganda), nos quais foram matriculados 369 estudantes, não tinham nenhum aluno "preto" conforme classificação do IBGE [...] (SILVA, 2016, p.140-141).

O racismo nas instituições escolares não se expressa apenas nas relações estabelecidas entre os educandos ou mesmo entre a comunidade escolar, mas nos materiais escolhidos, no acesso aos professores negros e negras, nos discursos privilegiados e currículo oculto ou não. Nas universidades não é diferente, as vozes que são ouvidas e as que são silenciadas, o olhar, as ideias que ecoam o espaço que cada um ocupa, as relações estabelecidas, tudo é reflexo da maneira como são encaradas as relações raciais e sociais. Silva (2016) ainda ressalta a relação entre o racismo sofrido pelos educandos negros e negras ao longo da trajetória escolar e o mito da democracia racial que, por vezes, relativiza as questões raciais e camufla o racismo presente em nossa sociedade.

Vale lembrar que os números refletem o racismo que marca negros e negras desde o início da vida escolar. Dizer que existe um funil racista no caminho que leva à universidade é pouco. A cada estágio da Educação aumenta o abismo que separa brancos e negros. Segundo o documento Situação Mundial da Infância 2011 (Unicef), no país da "democracia racial", um adolescente negro de 12 a 17, tem $42 \%$ mais chances de estar fora da escola do que um adolescente branco da mesma faixa etária. (SILVA, 2016, p.142)

Bem, esperamos ter demonstrado que, de forma deplorável, na USP, em particular há um enorme abismo entre a teoria, o discurso e a realidade. Um fosso tão amplo quanto aquele que separa as condições de vida de negros e brancos no nosso país, mas que, contudo, é sistematicamente encoberto por um mito que está incrustado na cabeça das pessoas (brancas e negras, diga-se de passagem) e, portanto, ganhou dimensões reais: a farsa de que vivemos numa democracia racial, onde o racismo é um crime inominável. (SILVA, 2016, p.151-152). 


\section{A democracia racial, a miscigenação e seus impactos na perpetuação do racismo e na construção das identidades étnico-raciais}

Como já foi ressaltado anteriormente, existe uma discussão acerca da tão propagada "democracia racial". Silva (2016) afirma que esse discurso tem origem na produção de Gilberto Freyre, Casa Grande e Senzala publicado em 1933.

Neste livro, Freire (2004) aborda a colonização do Brasil pelos portugueses através da miscigenação, subestimando o racismo e a luta de classes da época e, a meu ver, naturalizando a escravidão e o abuso cometido pelos escravocratas contra as escravas. Segundo o autor:

A miscigenação que largamente se praticou aqui corrigiu a distância social que de outro modo se teria conservado enorme entre a casa-grande e a mata tropical; entre a casa-grande e a senzala. O que a monocultura latifundiária e escravocrata realizou no sentido de aristocratização, extremando a sociedade brasileira em senhores e escravos, com uma rala e insignificante lambujem de gente livre sanduichada entre os extremos antagônicos, foi em grande parte contrariado pelos efeitos sociais da miscigenação. (FREIRE, 2004, p.33)

Formou-se na América tropical uma sociedade agrária na estrutura, escravocrata na técnica de exploração econômica, híbrida de índio - e mais tarde de negro - na composição. Sociedade que se desenvolveria defendida menos pela consciência de raça. Quase nenhuma no português cosmopolita e plástico, do que pelo exclusivismo religioso desdobrado em sistema de profilaxia social e política. (FREIRE, 2004, p.65)

É possível perceber nesses trechos retirados do livro como a realidade da época é retratada de maneira bastante natural, quase poética, relativizando a escravidão, a relação entre escravocratas e escravos, a miscigenação forçada, a opressão e a perda da liberdade, da cultura, da religiosidade e da identidade de negros e indígenas.

Sob o ponto de vista da miscigenação foram aqueles povoadores à-toa que prepararam o campo para o único processo de colonização que teria sido possível no Brasil: o da formação, pela poligamia - já que era escasso o número de europeus - de uma sociedade híbrida. (FREIRE, 2004, p.110)

Híbrida desde o início, a sociedade brasileira é de todas da América a que se constituiu mais harmoniosamente quanto às relações de raça: dentro de um ambiente de quase reciprocidade cultural que resultou no máximo de aproveitamento dos valores e experiências dos povos atrasados pelo adiantado; no máximo de contemporização da cultura adventícia com a nativa, da do conquistador com a do conquistado. (FREIRE, 2004, p.160)

Esses discursos de convívio harmonioso, "benevolente" entre as diferentes raças e povos que habitavam o nosso país e de miscigenação, que deu origem à ideia de embranquecimento da população, aos morenos, os pardos, aos que são negros de pele clara, surgiram como uma maneira de "unificar", universalizar o povo brasileiro, uma maneira de acalmar os ânimos dos negros e negras que começavam a construir sua consciência de raça e classe, a clamar e bradar por seus direitos. Infelizmente ainda hoje essa falsa ideia de união, de igualdade ainda ecoa e se propaga entre brancos e, o que é mais alarmante, entre negros em nosso país, dificultando seu reconhecimento e a construção de suas identidades étnico-raciais, bem como, a percepção das injustiças e violências sofridas, como destaca Silva (2016, p. 165):

Essa mesma lógica tortuosa que busca retirar a definição e a identidade raciais do campo sociológico, político e econômico, jogando-a para a "individualidade" determinada pelo tom de pele, não só é fundamental para a construção do mito da democracia racial como para o projeto de dominação que ele justifica, na medida em que é um obstáculo tanto para a percepção do racismo, pelos próprios negros e negras, quanto, consequentemente, para sua organização em movimentos e a construção de um senso de pertencimento coletivo. 
Sueli Carneiro (2011) também traz a problemática do uso da miscigenação em diferentes discursos em nossa sociedade e seu papel na propagação do mito da democracia racial como podemos ver nos trechos a seguir:

A miscigenação racial em nossa sociedade vem se prestando a diferentes usos políticos e ideológicos. [...] Em primeiro lugar a miscigenação vem dando suporte ao mito da democracia racial, na medida em que o intercurso sexual entre brancos, indígenas e negros seria o principal indicativo de nossa tolerância racial, argumento que omite o estupro colonial praticado pelo colonizador sobre mulheres negras e indígenas [...] (CARNEIRO, 2011, p.66)

Em segundo lugar, a miscigenação tem constituído um instrumento eficaz de embranquecimento do país por meio da instituição de uma hierarquia cromática e de fenótipos que têm na base o negro retinto e no topo o "branco da terra”, oferecendo aos intermediários o benefício simbólico de estar mais próximos do ideal humano, o branco. (CARNEIRO, 2011, p.67).

Atualmente o IBGE considera negros as pessoas que se autodeclaram pretas e pardas. Em um país tão miscigenado quanto o nosso, a autodeclaração está relacionada ao sentimento de pertencimento, identificação e nesse sentido podemos vislumbrar um pouco melhor a complexidade da construção da identidade étnico-racial dos sujeitos. Considerando a desigualdade social, o racismo, a violência e a vulnerabilidade aos quais os negros são submetidos em nossa sociedade, autodeclarar-se negro é um ato político, de coragem, de reconhecimento e resistência. No artigo Ser negro no Brasil: alcances e limites, a autora Fátima Oliveira aborda essa relação entre a miscigenação e a construção da identidade étnico-racial no Brasil:

O Brasil é um país mestiço, biológica e culturalmente. A mestiçagem biológica é, inegavelmente, o resultado das trocas genéticas entre diferentes grupos populacionais catalogados como raciais, que na vida social se revelam também nos hábitos e nos costumes (componentes culturais). No contexto da mestiçagem, ser negro possui vários significados, que resulta da escoIha da identidade racial que tem a ancestralidade africana como origem (afrodescendente). Ou seja, ser negro, é, essencialmente, um posicionamento político, onde se assume a identidade racial negra.

Identidade racial/étnica é o sentimento de pertencimento a um grupo racial ou étnico, decorrente de construção social, cultural e política. Ou seja, tem a ver com a história de vida (socialização/educação) e a consciência adquirida diante das prescrições sociais raciais ou étnicas, racistas ou não, de uma dada cultura. Assumir a identidade racial negra em um país como o Brasil é um processo extremamente difícil e doloroso, considerando-se que os modelos "bons", "positivos" e de "sucesso" de identidades negras não são muitos e poucos divulgados e o respeito à diferença em meio à diversidade de identidades raciais/étnicas inexiste. Desconheço estudos brasileiros consistentes sobre identidade racial/étnica. (OLIVEIRA, 2004, p.57).

Neste sentido, vemos como é difícil no Brasil a construção da identidade do povo negro, o que dificulta ainda mais sua consciência de raça e classe e por vezes faz negros reproduzirem discursos e ideias preconceituosas e racistas. É a dificuldade, e até mesmo o receio em reconhecer-se, a falta de pertencimento e o discurso ouvido tantas vezes que é internalizado, sem reflexão, e quase sem alternativa.

\section{Considerações finais}

Considerando toda essa complexidade, os desafios a serem superados pelas crianças e jovens negros e negras para a construção de seu pertencimento, seu reconhecimento, sua identidade étnica racial, torna-se urgente a reflexão sobre as relações estabelecidas na escola, entre educandos, entre professores e entre toda a comunidade escolar. Reconhecendo que não é possível deixar crianças negras sozinhas nesta luta, fechar os olhos para suas dificuldades, suas dores e violências sofridas, muitas delas dentro do espaço es- 
colar. Não é aceitável que, ao invés de compartilhar com elas e auxiliá-las neste caminho de autoconhecimento, constituição da autoestima e valorização pessoal, a escola reforce preconceitos, estereótipos e reproduza discursos preconceituosos e banalizadores, buscando naturalizar o inaceitável.

Assim como o bullying o racismo não é unilateral, quem o pratica também é afetado e também precisa de atenção. É preciso compreender que construir características positivas, aprender a conviver, cooperar, respeitar a diversidade e exercitar a empatia é um processo de construção que também ocorre na escola e requer intencionalidade, planejamento e acompanhamento. É através das interações, vínculos e relações que estabelecemos com o outro, com a cultura e com a diversidade que nos construímos e aprendemos. Sendo assim, o papel da escola e especialmente do professor é extremamente importante.

A educação tem o poder de transformar atitudes, ampliar a maneira como se vê e se age no mundo, na sociedade, nas relações. A escola não pode se furtar dessa responsabilidade transformadora, que amplia olhares, discursos e reflexões. O discurso de formarmos cidadão críticos, solidários, conscientes, capazes de transformar a si e a sociedade não pode ser apenas um discurso, as instituições escolares precisam rever suas concepções e práticas e analisar quais as ações realizadas para que de fato os educandos possam ser capazes de agir e transformar o mundo, a sociedade com vistas à uma cultura de paz, ao bem comum, ao respeito e à equidade.

Quando dizemos que o racismo vem sendo camuflado pelo bullying não queremos diminuir os impactos que o bullying causa, ou minimizar a importância de seu real combate, mas buscamos destacar que são violências distintas, o racismo tem uma origem, um alvo, uma motivação distinta e é preciso considerar estas questões e suas implicações para combatê-lo.

A nossa história, a maneira como o nosso país e o nosso povo foi constituído, as lutas, as dores não devem ser fantasiadas, folclorizadas, minimizadas. Houve sofrimento, houve um povo subjugado, houve ausência de direitos. Sendo assim, cabe a cada um pensar até quando isso irá se repetir, até quando direitos serão negados, até quando crianças, jovens e adultos sofrerão violência, injustiça e preconceito por sua cor. Refletir sobre responsabilidades, individuais e coletivas, sobre a necessidade de mudança para o alcance de uma sociedade mais justa, que considere, acolha e beneficie a todos sem universalizar o povo, sem o discurso de somos todos iguais, somos humanos, mas reconhecendo sim nossas diferenças, nossas tradições, nossa cultura, nossa pluralidade e percebendo a riqueza dessa diversidade com respeito e equidade.

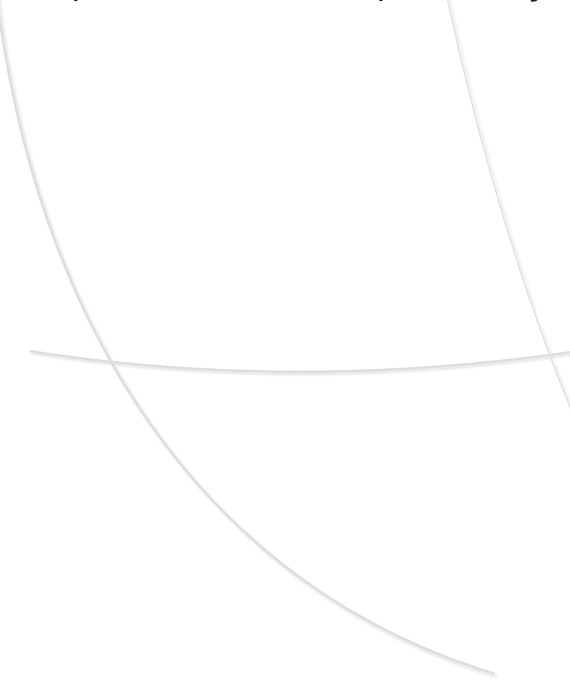




\section{REFERÊNCIAS}

BRASIL. Lei $n^{\circ} 10.639 / 2003$, de 09 de janeiro de 2003. Disponível em: http://www.planalto.gov.br/ ccivil 03/leis/2003/L10.639.htm. Acesso em: 10 mar. 2019.

CARNEIRO, Sueli. Racismo, sexismo e desigualdade no Brasil. São Paulo: Selo Negro, 2011.

CAVALLEIRO, Eliane dos Santos. Do silêncio do lar ao silêncio escolar: racismo, preconceito e discriminação na educação infantil. 1998. 240 f. Dissertação (Mestrado em educação) - Faculdade de Educação, Universidade de São Paulo Faculdade de Educação, São Paulo, 1998.

FREIRE, Gilberto. Casa grande e senzala: formação da família brasileira sob o regime da economia patriarcal. 49. ed. São Paulo: Global, 2004.
OLIVEIRA, Fátima. Ser negro no Brasil: alcances e limites. Estudos Avançados, v. 18, n. 50, p.5760, abr. 2004. Fap UNIFESP (SciELO). Disponível em: http://dx.doi.org/10.1590/s0103-40142004000100006. Acesso em: 23 out. 2019.

SILVA, Elizângela Napoleão da; ROSA, Ester Calland de S. Professores sabem o que é bullying?: um tema para a formação docente. Revista Semestral da Associação Brasileira de Psicologia Escolar e Educacional, v. 17, n. 2, p.329-338, jun. 2013.

SILVA, Wilson Honório da. O mito da democracia racial: um debate marxista sobre raça, classe e identidade. São Paulo: Sundermann, 2016.

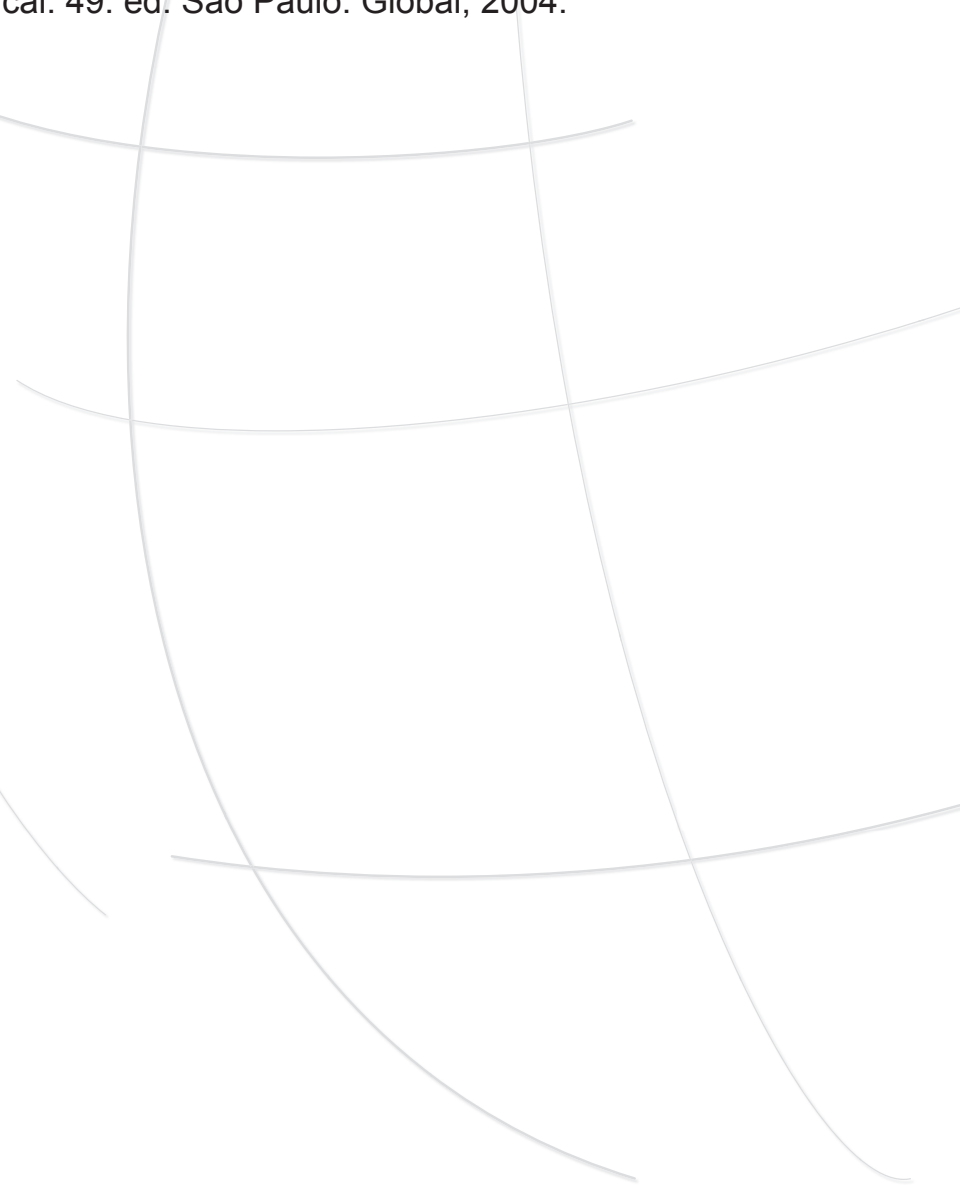

